\title{
A Produção de Contra-Argumentos na Escrita Infantil
}

\author{
Selma Leitão ${ }^{1,2}$ \\ Eliana G. da S. Almeida \\ Universidade Federal de Pernambuco
}

\begin{abstract}
Resumo
Pesquisas sobre a produção de textos argumentativos mostram que antecipar contra-argumentos e reagir a estes é uma das principais dificuldades na escrita deste tipo de texto. Este estudo investigou a habilidade de 157 crianças (segunda, quarta e sétima séries) gerarem contra-argumentos nos textos que produziam. Observou-se que, embora contra-argumentos apareçam ocasionalmente nos escritos da segunda série, só a partir da quarta essa presença se torna sistemática. Progressos relacionados à idade e escolaridade foram também registrados quanto ao número de contra-argumentos examinados num mesmo texto. A estrutura global dos textos produzidos (narrativo $v s$. opinativo) e o tema discutido não parecem ter afetado a produção de contra-argumentos pelas crianças, embora efeitos destes fatores tenham sido notados sobre o número de idéias usadas pelas mesmas para justificarem suas própria posições. Na discussão destes resultados examina-se o papel de fatores pragmáticos no desenvolvimento de contra-argumentos em textos escritos.

Palavras-chave: Argumentação; contra-argumentos; escrita argumentativa; produção de texto.
\end{abstract}

Counterargument in Children's Writing

Abstract

Studies on argumentative text writing have shown that anticipating counterargument and reacting to them is one of the hardest demands of argumentative writing. The present study focused on second, fourth, and seventh graders' ability to generate counterarguments in their writings. The results showed that, although counterarguments appear in some of the second graders' writings, it is only after the fourth grade that their presence is systematically observed in children's writing. Age- and schoolingrelated effects were also noted on the number of counterarguments examined per text. The global structure of the texts produced (a narrative vs. an opinion text) did not affect the production of counterargument by children, although a main effect of such factors was noted on the number of ideas children used to justify their own views. The role of pragmatic factors in the development of counterargument in written texts was taken into account when discussing these findings.

Keywords: Argumentation; counterargument; argumentative writing; text production.

A argumentação é geralmente descrita como uma atividade social e de natureza discursiva na qual indivíduos que expressam pontos de vista divergentes sobre um tema defendem suas posições com vistas ao convencimento de seus interlocutores (Eemeren, Grootendorst \& Kruiger, 1987). Nesta perspectiva a argumentação se define, portanto, como uma atividade de natureza

${ }^{1}$ Endereço para correspondência: Universidade Federal de Pernambuco, Pós-Graduação em Psicologia. CFCH, $8^{\circ}$ andar, Cidade Universitária, 50670901, Recife, PE. Fone: (81) 2718272, Fax: (81) 2711843. E-mail:

slsantos@npd.ufpe.br
2 O estudo descrito neste artigo é parte de um projeto desenvolvido na 2 O estudo descrito neste artigo é parte de um projeto desenvolvido na
Pós-Graduação em Psicologia da UFPE, que investiga a produção de Pós-Graduação em Psicologia da UFPE, que investiga a produção de
textos argumentativos por crianças e adolescentes. O estudo fez parte da textos argumentativos por crianças e adolescentes. O estudo fez parte da
Monografia de Conclusão do Curso de Bacharelado em Psicologia da segunda autora, sob orientação da primeira. Resultados preliminares foram apresentados no Segundo Congresso Brasileiro de Psicologia do Desenvolvimento, Maio/1998 e na 50" Reunião Anual da SBPC, Julho/ 1998. As autoras agradecem o apoio recebido do CNPq sob a forma de bolsas de pesquisa e financiamento de projeto. eminentemente dialógica (envolve multiplicidade de perspectivas) e dialética (pressupõe oposição).

Se tomada em seu sentido mais estrito, a ênfase na dimensão dialógica da argumentação implicaria sempre na presença mínima de dois interlocutores para que esta se constituísse num dado contexto discursivo. Esse porém não é o caso. De fato não é difícil constatar-se que a argumentação em situações de monólogo, como palestras, textos escritos, etc., é atividade amplamente presente no quotidiano dos indivíduos. O que se ressalta, no entanto, é que mesmo em situações de monólogo, ou naquelas em que um indivíduo se engaja na argumentação apenas consigo mesmo a respeito de um tema, é ainda o diálogo o modelo que estrutura a forma que a argumentação assume. Em tais situações, o diálogo se realiza pela presença de um interlocutor imaginário a quem a argumentação se dirige (o convencimento de um outro é sempre o fim último da argumentação) e cuja voz (no sentido bakhtiniano discutido em Holquist, 1990 e 
Werstch, 1991) traz para o contexto da argumentação um elemento de oposição (pontos de vista alternativos, contra-argumentos, etc.) indispensável à sua realização. É portanto o confronto entre pontos de vista, e não entre indivíduos, o elemento que confere à argumentação sua dimensão dialógica/dialética.

Entendida desta maneira, a argumentação se define como um espaço de negociação (Roussey \& Gombert 1996) no qual argumentos ${ }^{3}$ apresentados estão sujeitos a contestação e podem, em conseqüência disto, se expandidos, retirados pelos seus proponentes ou ainda transformados em aspectos crucias (Leitão, no prelo). A criação de um tal espaço de negociação no discurso é processo cuja complexidade não deve ser subestimada sobretudo quando este é produzido em situações de monólogo, como é o caso da escrita. As dificuldades inerentes a este processo têm de fato sido vistas como um dos obstáculos centrais a serem superados pelos indivíduos antes que se tornem produtores competentes de argumentação na escrita (Andriessen, Coirier, Roos \& Passerault \& Bert-Erboul, 1996; Coirier, 1996; De Bernardi \& Antolini, 1996; Dolz, 1996; Golder \& Coirier 1994; Roussey \& Gombert, 1996).

Justificação e Negociação: As Operações Básicas da Argumentação

No plano psicolingüístico, o estabelecimento de um espaço de negociação no âmbito de um texto escrito exige do indivíduo a realização de duas operações básicas. A primeira, a justificação, consiste na explicitação de uma ou mais razões que conferem apoio a um ponto de vista proposto (Coquin \& Coirier, 1992). A segunda, negociação propriamente dita, envolve a utilização de uma variedade de recursos lingüísticos e cognitivos por meio dos quais o escritor demonstra reconhecer a existência de pontos de vista alternativos e objeções à sua posição $\mathrm{e}$ empenha-se em conseguir a adesão de seu interlocuto ao seu ponto de vista (Coirier, Coquin, Golder \& Passerault, 1990; Espéret, Coirier, Coquin \& Passerault, 1987; Golder \& Coirier, 1996). A presença de ambas as operações num texto tem sido vista como definidora de uma atividade argumentativa elaborada, em contraste com a argumentação mínima na qual apenas a justificação se faz

${ }^{3}$ Note-se que, como usado no presente texto, o termo argumento design um conjunto de enunciados no qual pelo menos um é apresentado en defesa do outro. De forma análoga, o termo contra-argumento é usado para referir-se a uma idéia que, num contexto argumentativo específico, funciona como um ataque a um argumento. Em coerência com estes usos, os termos argumentar e contra-argumentar são usados, respectivamente, para designar as ações de produzir argumentos e antecipar contraargumentos. presente (Andriessen e cols., 1996; De Bernardi \& Antolini, 1996; Golder, 1992; Golder \& Coirier, 1994, 1996)

Diversos são os recursos lingüísticos que permitem ao escritor criar um espaço de negociação num texto escrito. Golder e Coirier (1996) descrevem como essenciais a este propósito, o uso de expressões de incerteza (eu acho, eu penso, talvez, etc.) e avaliação (é bom, é absurdo, devo, prefiro, etc.), bem como a referência explícita a contra-argumentos. $\mathrm{O}$ uso das primeiras permite ao indivíduo apresentar suas idéias como julgamentos sobre fatos, abrindo com isto o caminho da negociação de seus pontos de vista. A consideração de contraargumentos, por sua vez, torna explícito que o autor reconhece a existência de posições contrárias, constituindo-se portanto num recurso de negociação por excelência.

O manejo de contra-argumentos em situações de diálogo oral manifesta-se quase sempre na forma de uma reação do falante a argumentos levantados por um interlocutor, embora não se ignore naturalmente a possibilidade do próprio falante antecipar objeções que lhe poderiam ser apresentadas por outrem. Nos monólogos escritos, diferentemente, a consideração de contra-argumentos se torna possível apenas pela antecipação, pelo próprio escritor, de restrições e críticas que um leitor poderia levantar em relação às suas posições.

O presente artigo focaliza de modo específico a presença de contra-argumentos em textos escritos. Mais precisamente, interessa-nos investigar em que medida crianças e adolescentes de diferentes idades e níveis de escolaridade (indivíduos portanto que se encontram em processo de aquisição tanto das habilidades de raciocínio como dos recursos lingüísticos necessários à argumentação) lidam com o contra-argumento nos textos que produzem e como gradualmente evoluem no manejo deste aspecto específico da escrita argumentativa.

Produção de Justificativas e Contra-Argumentos na Argumentação Infantil

Estudos recentes na área do desenvolvimento de habilidades de argumentação em crianças demonstram que o processo que as leva ao domínio do discurso argumentativo é marcado por assimetrias em dois importantes aspectos. Primeiramente, se comparada à habilidade de gerar idéias de apoio a um ponto de vista (justificativas), a possibilidade de considerar posições alternativas e antecipar contra-argumentos é vista como uma ocorrência mais tardia no desenvolvimento da criança (De Bernardi \& Antolini, 1996; Golder, 1992; Golder \& Coirier, 1994; Miller, 1987; Santos, 1997). Estudos mostram que já por volta dos quatro a cinco anos as Psicologia: Reflexão e Crítica, 2000, 13(3), pp.351-361 
crianças são capazes de definir pontos de vista e justificar posições numa variedade de situações de diálogo. Além disto, são capazes de se oporem a pontos de vistas de outros e de ajustarem seus argumentos no sentido de torná-los aceitáveis a interlocutores diferentes (BanksLeite, 1996; Miller, 1987; Orsolini, 1994). Apesar dessa aparente precocidade com que se pode observar habilidades de argumentação nas crianças, importantes progressos ainda serão necessários antes que estas se tornem capazes de desenvolver uma estrutura de argumentação escrita elaborada, ou seja, uma estrutura na qual não apenas justificativas para os pontos de vista propostos são apresentadas mas também posições alternativas e contra-argumentos são sistematicamente antecipados. Tal nível de desenvolvimento não parece ser completamente alcançado até a idade de quinze ou dezesseis anos (De Bernardi \& Antolini, 1996; Golder \& Coirier, 1994).

A segunda assimetria que parece caracterizar o desenvolvimento de habilidades de argumentação em crianças é observada quando se compara os desempenhos das mesmas na argumentação oral e na escrita. Em contraste com a relativa facilidade com que as crianças justificam pontos de vista e lidam com oposição em situações de diálogo oral, a realização das mesmas operações na escrita parece ser uma tarefa consideravelmente mais árdua (De Bernardi \& Antolini, 1996; Dolz, 1996; Golder \& Coirier, 1996; Santos, 1997). Nesse sentido, particularmente difícil parece ser para as crianças, o manejo de contra-argumentos num texto escrito. Disso se conclui que a tendência a examinar prós e contras no âmbito de um texto escrito não é algo a ser esperado das crianças apenas porque estas já se mostram capazes de argumentar e contra-argumentar em situações de diálogo oral e já adquiriram habilidades básicas de composição textual. Em outras palavras, nenhuma transferência automática de habilidades de argumentação deve ser esperada quando a criança passa da argumentação oral para a escrita. Diante de constatações como estas, duas perguntas surgem de imediato: o que torna argumentação na escrita, e particularmente o manejo de contra-argumentos, tão difícil para as crianças e como estas gradualmente adquirem as habilidades necessárias à produção competente deste gênero textual.

Diversos fatores têm sido apontados na literatura como responsáveis pelas dificuldades enfrentadas pelas crianças quando se engajam na escrita argumentativa. Entre esses cita-se, por exemplo, o domínio incipiente dos recursos lingüísticos necessários à definição de uma estrutura textual em que prós e contras um dado tema se incorporem de modo coerente e coeso (Feilke, 1996; Kail Psicologia: Reflexão e Crítica, 2000, 13(3), pp.351-361
\& Weissenborn, 1991; Schneuwly, 1997; Vieira, 1994). Ou ainda problemas que parecem advir da própria natureza dos temas que favorecem o surgimento de argumentação, temas controversos e que remetem freqüentemente a conceitos definidos de modo vago e impreciso (Golder \& Coirier, 1994; Perera, 1984). Mas é sobretudo uma terceira fonte de dificuldade, freqüentemente invocada quando se tenta explicar as assimetrias mencionadas acima, que merece especial atenção aqui. De acordo com esta explicação, as diferentes condições em que os discursos argumentativos oral e escrito são produzidos respondem parcialmente tanto pela maior dificuldade de produção de escrita argumentativa, em relação à argumentação oral, quanto pela maior dificuldade no manejo da contraargumentos, quando comparado ao de justificativas (De Bernardi \& Antolini, 1996; Dolz, 1996).

A argumentação oral ocorre tipicamente em situações de diálogo nas quais a presença, na situação imediata em que a argumentação ocorre, dos indivíduos que defendem posições contrárias possibilita que esta se distribua entre os vários participantes do evento. O que se observa caracteristicamente em tais situações é que, enquanto a produção de justificativas para um ponto de vista fica a cargo de quem o propõe, o levantamento de contraargumentos é realizado por um ou mais interlocutores que assumem o papel de oponentes em relação ao ponto de vista em questão. Em tais condições, a argumentação se realiza de modo essencialmente colaborativo. À medida que proponente e oponente se alternam na apresentação de argumentos e contra-argumentos, respectivamente, gera-se uma estrutura discursiva em que a conexão entre pontos de vista opostos é construída a partir da própria alternância dos falantes.

Situação bem diversa cerca a produção da escrita. $\mathrm{Na}$ condição solitária em que esta geralmente ocorre, a produção de justificativas e contra-argumentos depende apenas do escritor. É a este, exclusivamente, que cabe o papel de explicitar e justificar seu ponto de vista bem como o de antecipar e reagir a possíveis objeções e posições contrárias. Neste caso é possível dizer-se que cabe ao escritor a tarefa de falar por dois (Scinto, 1986), por si mesmo e por um oponente (virtual), de sorte a integrar, no corpo de um único texto, as diferentes vozes que coexistem no discurso argumentativo. Além disto, apenas a consideração de prós e contras não gera por si só um texto argumentativo. Para tanto, o escritor deve ainda ser capaz de expressar as idéias produzidas dentro de uma seqüência linear que respeite as convenções que regem o uso da linguagem. E mais: é preciso ser capaz de conectar argumentos e contra-argumentos dentro de uma estrutura textual que reflete a dimensão dialógica do 
discurso argumentativo, ao mesmo tempo que expõe de modo não ambíguo as posições que são defendidas e as que são examinadas e refutadas. A necessidade de gerar um diálogo desta natureza dentro uma atividade monológica, a escrita, aumenta consideravelmente o nível de complexidade das operações lingüísticas envolvidas na produção de contra-argumentos, se comparada às requeridas para a produção de justificativas.

Se esta explicação é correta, deveria ser possível auxiliar escritores aprendizes a manejarem contra-argumentos na escrita se a necessidade de considerar a perspectiva de um oponente se tornasse mais explícita na situação de produção textual. Por exemplo, se elementos do próprio texto a ser escrito funcionassem como pista auxiliar para a antecipação de contra-argumentos. Esta hipótese foi levantada por Santos e Vasconcelos (1997) a partir da reflexão sobre os resultados de dois estudos, independentemente realizados, nos quais a presença de contra-argumentos na escrita infantil foi analisada.

No estudo de Vasconcelos (1998), a autora apresentava a alunos das segunda, quarta e sétima séries o início de uma narrativa na qual duas crianças divergiam a respeito de uma decisão que deveriam tomar: se ao verem um colega fumando na escola, deveriam ou não relatar o fato à professora. Pedia-se então às crianças que concluíssem a narrativa gerando uma discussão entre os personagens até que os mesmos chegassem a um acordo. Um resultado que chama a atenção neste estudo é que o número de contra-argumentos (idéias que se opunham à posição defendida pelo personagem com quem a criança concordava, o protagonista) que aparecia nos textos produzidos pelas crianças foi em média mais alto que o observado quando crianças, aproximadamente do mesmo nível de escolaridade (segunda, quinta e oitava séries), foram solicitadas a escrever textos de natureza opinativa sobre o tema: quem deveria escolher os programas a que as crianças assistem na televisão, ela próprias ou seus pais (Santos, 1997). A hipótese sugerida pelas autoras foi a de que a presença, no texto, de personagens que divergiam e aos quais crianças deveriam dar voz, de certa forma as forçaria a considerar os prós e os contras do tema, funcionando assim como uma pista intratextual para a produção de contra-argumentos (Santos \& Vasconcelos, 1997). Diferenças quanto aos níveis exatos de escolaridade das crianças e aos temas sobre o qual as crianças escreviam não permitiram, no entanto, que maiores comparações fossem feitas entre os resultados dos dois estudos.

Diante das considerações feitas acima três objetivos complementares estiveram na base do presente estudo. Em primeiro lugar, interessou-nos investigar em que medida crianças de diferentes níveis de escolaridade tendem a criar uma estrutura dialógica quando se engajam em argumentação na escrita, ou seja, uma estrutura em que não apenas um ponto de vista é proposto e justificado, mas no mínimo um contra-argumento é examinado. Com isto espera-se obter um perfil do desempenho de crianças brasileiras que sirva de referência tanto na comparação com dados obtidos com crianças de diferentes experiências culturais e educacionais, como para estudos subseqüentes que focalizem o desenvolvimento da escrita argumentativa. Além disto, interessou-nos investigar não só a presença de contra-argumentos nos textos infantis, mas também o grau de elaboração que a produção de contra-argumentos alcança nos mesmos. O terceiro e último interesse foi testar duas hipóteses levantadas a partir da comparação dos resultados dos estudos de Santos (1997) e Vasconcelos (1998) mencionados acima. A primeira é que o exame de contra-argumentos no âmbito de um texto escrito poderia ser favorecido pela presença explícita, no texto, de um protagonista e um antagonista a quem o escritor deve dar voz no curso da escrita. A idéia subjacente a esta hipótese é a de que a presença do antagonista cumpriria de certa forma um papel análogo (embora muito menos explícito, naturalmente) ao que o oponente desempenha em situações de diálogo oral. Finalmente, testava-se a hipótese de que variações quanto ao tema discutido pelos indivíduos poderiam ter um impacto sobre a extensão com que estes consideram contra-argumentos nos seus escritos.

\section{Método}

\section{Participantes}

Participaram deste estudo 157 crianças e adolescentes, alunos das segunda $(n=48)$, quarta $(n=51)$ e sétima séries $(n=58)$ do Ensino Fundamental de uma escola particular.

\section{Material}

Folhas de papel contendo o desenho de um televisor ou um cigarro na margem superior direita; folhas contendo o início de uma narrativa sobre um dentre dois temas (os temas e textos usados são descritos na seção a seguir).

\section{Tarefa Proposta aos Participantes}

A todas as crianças foi solicitada a produção de um texto sobre um tema proposto imediatamente antes da escrita do mesmo. Para a realização desta tarefa, quatro condições de produção foram criadas nas quais se variava dois elementos: o tema da escrita e a estrutura global do texto solicitado. Em qualquer destas condições, os textos 
foram produzidos durante as atividades regulares da disciplina de Comunicação e Expressão e sem que se impusesse limites ao tempo gasto na escrita dos mesmos. Embora os professores das turmas pesquisadas estivessem presentes, a atividade proposta aos alunos foi coordenada por um membro da equipe de pesquisa e sem qualquer interferência da parte daqueles.

À metade dos alunos das turmas A de cada série (em todas as séries os alunos estavam distribuídos, por ordem de matrícula, em turmas A e B) se pediu que escrevessem livremente o que pensavam a respeito do tema: quem deveria escolher os programas a que as crianças assistem na TV, se as próprias crianças ou os seus pais (texto opinativo, tema TV). À outra metade dos alunos das mesmas turmas se solicitou igualmente a produção livre de um texto, desta feita sobre o tema: se ao ver um colega fumando na escola (uma ação proibida), um aluno deveria ou não relatar o fato à professora (texto opinativo, tema (igarro). Na apresentação de ambos os temas, as instruções deixavam clara a oposição entre as duas posições mencionadas em cada tema. Após as instruções, folhas de papel contendo um pequeno desenho (uma TV ou um cigarro) na margem superior direita foram aleatoriamente distribuídas entre os alunos de cada série nas quais deveriam escrever os seus textos. Os desenhos inseridos nas folhas indicavam a cada aluno sobre qual dos dois temas deveria escrever.

Idênticos temas foram propostos aos alunos das turmas B de cada série, embora neste caso lhes tenha sido solicitada a produção de um texto de estrutura diferente da requerida dos alunos das turmas A. Seguindo-se o procedimento adotado por Vasconcelos (1998), apresentava-se aos alunos o início de uma narrativa em que dois personagens divergiam em relação a um tema que discutiam. O início da narrativa definia claramente o tema da controvérsia, os personagens e o ponto de vista que cada um deles defendia. Pedia-se então às crianças que concluíssem a narrativa escrevendo a discussão entre os dois personagens até que estes chegassem a uma conclusão sobre o assunto em questão. À metade dos alunos das turmas $\mathrm{B}$ de cada série o início de narrativa era apresentado nos seguintes termos: Maria e Sílvia (Mário e Sílvio nas narrativas apresentadas aos meninos) estão conversando sobre um programa de TV a que elas gostariam de assistir mas seus pais não deixam. Maria acha que quem deve escolher os horários e os programas a que as crianças assistem são os pais, mas Silvia acha que quem deve escolher os horários e os programas a que as crianças assistem são as próprias crianças. Elas duas têm que chegar a um acordo: quem deve escolher os horários e os programas a que as crianças assistem na TV (texto narrativo, tema TV).

Psicologia: Reflexão e Crítica, 2000, 13(3), pp.351-361
À segunda metade dos alunos das mesmas turmas um outro início de texto era apresentado: Maria e Sílvia vêem seu colega fumando escondido. Maria acha que deve contar à professora, mas Sillvia acha que não deve. Elas duas têm que chegar a um acordo: contar ou não contar para a professora (texto narrativo, tema Cigarro). A estes mesmos alunos pediase ainda que indicassem no verso da folha com qual dos personagens eles concordavam, objetivando-se com isto tornar explícito o ponto de vista do escritor.

\section{Procedimento de Análise dos Dados}

$\mathrm{Na}$ identificação de contra-argumentos nos textos analisados foram adotados os procedimentos e definições propostos em Santos (1993). Entende-se como contraargumento qualquer idéia mencionada no curso de uma argumentação, que direta ou indiretamente enfraqueça o ponto de vista defendida pelo proponente de um argumento. Observe-se que ao termo contra-argumento não se confere aqui o sentido estrito de elemento falseador de uma afirmação e, sim, um sentido amplo no qual se incluem quaisquer idéias que potencialmente reduzam a possibilidade de aceitação de um ponto de vista. Estes enunciados consistem tipicamente em idéias que poderiam dar sustentação a uma posição contrária à do proponente (demonstram que posições alternativas são defensáveis), dúvidas quanto à veracidade de idéias com as quais o proponente justifica sua posição (questionam a aceitabilidade das premissas de um argumento), ou dúvidas quanto a relevância de uma idéia em relação ao ponto de vista que esta supostamente justifica (Leitão, no prelo).

Contra-argumentos são geralmente introduzidos no discurso por concessivas e conectivos de oposição tais como: embora, ainda que, mas. Note-se, no entanto, que a presença destes operadores argumentativos (Koch, 1984), por si só, quase nunca pode ser tomada como um indicador inequívoco da presença de contra-argumentos. A multiplicidade de usos possíveis para palavras e expressões como as acima é uma das razões que impedem que da presença destes operadores se infira de modo direto a presença de contra-argumentos. Além desta, os diferentes níveis de habilidade lingüística dos indivíduos são muitas vezes responsáveis pelo surgimento de usos idiossincráticos destes operadores. Esta observação se torna particularmente importante em estudos que, como este, investigam a produção de textos por escritores cujas habilidades lingüísticas estão ainda em desenvolvimento. Finalmente, é sabido que a apresentação de elementos de oposição sem qualquer marcador lingüístico explícito é ocorrência freqüente e legítima na fala e na escrita quotidianas (Schiffrin, 1992). 
Em vista do exposto, dois critérios foram adotados para identificação de contra-argumentos (Santos, 1993). Primeiro, um enunciado contém um contra-argumento se conectado à posição defendida pelo escritor por meio de um marcador típico de oposição (mas, etc.), torna-se explícita a forma como o primeiro potencialmente reduz a aceitabilidade do segundo. Ainda: um enunciado contém um contra-argumento se, uma vez reconstruído o texto sob análise na forma de um diálogo escritor-oponente o enunciado em questão pode ser visto como parte da vOz do oponente (isto é, como um desafio à posição do escritor). Procedimentos análogos foram adotados na identificação de justificativas nos textos das crianças (definidas como quaisquer elementos que ofereçam apoio à posição do autor). A análise do texto de uma aluna da segunda série transcrito abaixo ilustra os procedimentos adotados. A transcrição apresentada preserva as características gerais do texto no que diz respeito à ortografia, pontuação, ausência de título, grifos, etc

1. Alguas criança prefere que ela mesmo escolha o

2. canal da televisão. Mas os pais Não deixa por

3. causa dos fimes de luta de mata e de facada

4. porque as criança Quando assiste faz a

5. mesma coisa e casa então minha opinião

6. foi essa

FIM

A primeira característica que se destaca no texto acima é a ausência de uma afirmação mais explícita do ponto de vista da autora. Não se torna inteiramente claro se autora se inclui entre as crianças mencionadas na linha 1 ou se o seu ponto de vista coincide com o dos pais, referido nas linhas 2-5. O uso do pronome essa (linha 6) sem menção clara ao que o mesmo se refere, cria certa ambigüidade no texto. $\mathrm{O}$ ponto mais importante a se notado, no entanto, é que este nível de ambigüidade (previsível em textos de indivíduos cujas habilidades gerais de composição textual estão em desenvolvimento) não impede que se identifique o texto em pauta como de natureza claramente argumentativa. Para tanto, as perguntas críticas às quais sua análise precisa responder são: se o texto reflete a dimensão dialógica da argumentação e em que medida justificação e negociação, operações definidoras da argumentação, são ambas realizadas no mesmo.

Em relação à primeira pergunta, a resposta é certamente afirmativa. É clara a polarização que a autora estabelece entre as opiniões de crianças e pais, os interlocutores do diálogo criado no texto. Note-se que a opinião atribuída às crianças aparece no texto apenas na forma de afirmação de um ponto de vista ("crianças preferem que elas mesmas escolham o canal da televisão", linhas 1-2).
Nenhuma razão é apresentada que justifique o ponto de vista proposto. Imediatamente após explicitar o ponto de vista pró criança (linha 2), a escritora considera que os pais não deixam que as crianças escolham os programas, do que se infere que, na opinião destes, a eles deve caber esta escolha. Com isto um segundo ponto de vista, o dos pais, é incorporado ao texto. A passagem da VOZ das crianças para a dos pais (nesta espécie de diálogo virtual), bem como a oposição entre os pontos de vista destes interlocutores são marcadas de modo preciso pelo uso da adversativa mas. A razão que suporta o ponto de vista dos pais é clara: a televisão mostra programas violentos ("filmes de lutar, de matar e de facada", linha 3) que influenciam negativamente o comportamento das crianças ("a criança ... faz a mesma coisa em casa", linhas 4-5). O conteúdo do ponto de vista dos pais e o da razão com que o mesmo é justificado, ambos põem em xeque o ponto de vista das crianças, cumprindo portanto a função de contra-argumento em relação a este.

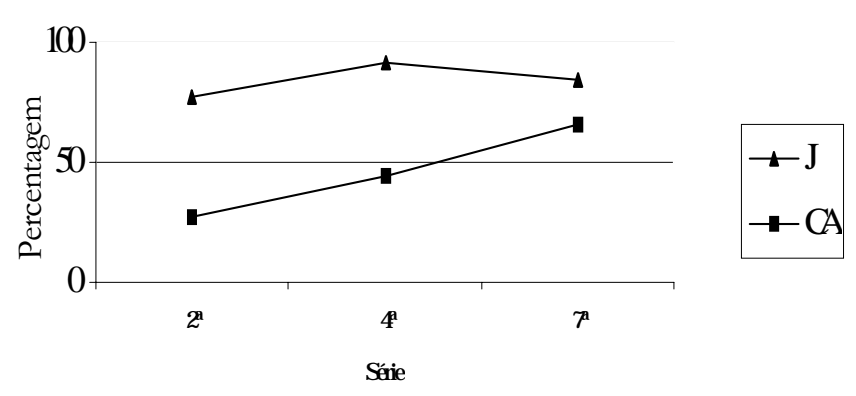

Figura 1. Percentual de textos contendo justificativa $(J)$ e contra-argumento (CA) por série

Esta análise permite também que se responda à segunda pergunta mencionada no parágrafo anterior, qual seja: em que medida justificação e negociação, as operações constitutivas da argumentação, se realizam no texto em pauta. Tomando-se como referência o ponto de vista das crianças, considera-se que dois elementos são identificáveis no texto: um ponto de vista pró criança (não justificado) e um contra-argumento para o mesmo (na forma de uma idéia que justifica o ponto de vista contrário).

${ }^{4} \mathrm{O}$ termo polifonia refere-se aqui ao fenômeno pelo qual diferentes vozes (Holquist, 1990; Werstch, 1991) se integram num discurso numa espécie de diálogo entre pontos de vista. Neste sentido, a polifonia é tida como uma dimensão constitutiva da argumentação (para uso semelhante do termo ver, por exemplo, Coirier, 1996). 


\section{Resultados}

\section{Dimensão Dialógica na Escrita Argumentativa} Infantil

A primeira pergunta a que o presente estudo procurou responder foi em que medida a escrita argumentativa produzida por crianças de diferentes níveis de escolaridade reflete a dimensão dialógica (ou polifônica) ${ }^{4}$ que caracteriza o discurso argumentativo. Ou seja, em que medida escritores aprendizes tendem a, no âmbito de um único texto, criar uma estrutura de justificação para o ponto de vista que defendem e antecipar possíveis contraargumentos a que este está sujeito. A Figura 1 abaixo mostra a percentagem de redações, por série, em que justificativas e contra-argumentos foram identificados. Dos dados apresentados em seguida foram excluídos oito textos (quatro da segunda, três da quarta e um da sétima série) considerados não argumentativos (textos nos quais não foi possível identificar qualquer ponto de vista) e o protocolo de um aluno que nada produziu.

A identificação de justificativas e contra-argumentos foi realizada por dois juizes que trabalharam de forma independente sobre $77 \%$ dos textos analisados, obtendose um índice de concordância de 89\%. Casos de desacordo foram resolvidos na discussão entre os mesmos. O restante dos textos, cuja categorização não se mostrou de modo algum problemática, foi analisado por um dos julgadores.

Conforme se observa na Figura 1, a justificação de pontos de vista em textos escritos é operação que não parece oferecer maiores dificuldades para as crianças dos grupos considerados. Mesmo entre os escritores mais jovens, $77 \%$ a realizam, percentual que atinge as marcas dos $91 \%$ e $83 \%$ nas quarta e sétima séries, respectivamente, embora tais diferenças não se mostraram significativas no tratamento com o Qui-quadrado. Estes resultados são consistentes com os de estudos realizados com crianças italianas (De Bernardi \& Antolini, 1996) e francesas

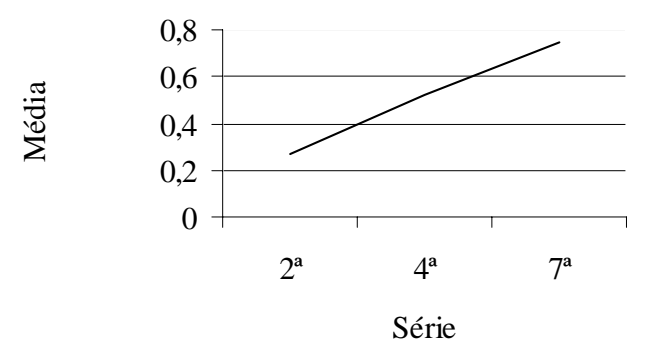

Figura 2. Número médio de contra-argumentos por sér.
(Golder \& Coirier, 1996) e confirmam os obtidos no estudo piloto realizado com uma pequena amostra de crianças brasileiras (40 alunos de quatro séries dos ensinos fundamental e médio) relatado em Santos (1997). O domínio da operação de justificação é ocorrência precoce no desenvolvimento da escrita argumentativa das crianças sendo já observado no início da escolarização básica.

Em relação ao manejo de contra-argumentos na escrita argumentativa, no entanto, o quadro observado é bem diverso. À primeira vista ressalta-se o fato de que a presença de contra-argumentos é registrada em textos produzidos por escritores de todos os níveis de escolaridade observados. Note-se entretanto que o percentual de indivíduos que produziram contraargumentos em cada grupo varia significativamente com idade e grau de escolaridade. Enquanto apenas $27 \%$ dos escritores de segunda série se referem a posições alternativas quando argumentam, este percentual chega a $43 \%$ na quarta série e alcança a marca de $66 \%$ nos textos dos alunos da sétima série $\left(\mathrm{x}^{2}(2)=15,23, p<0,0005\right)$. Uma vez mais a tendência observada coincide com a descrita por Golder e Coirier $(1994,1996)$ e confirma os resultados obtidos no estudo piloto de Santos (1997) citado acima. Tomados em seu conjunto, estes resultados definem uma fase crítica na qual contra-argumentos aparecem de modo sistemático na escrita infantil, notadamente em torno da quarta série (dez-onze anos).

\section{Nível de Elaboração de Contra-Argumentos na} Escrita Infantil

Embora a presença de contra-argumentos num texto seja vista como indicadora de maior elaboração na escrita argumentativa (comparada àquela em que apenas operações de justificação se fazem notar), a mera referência a uma posição contrária por certo não esgota os níveis de elaboração que a argumentação pode alcançar. A pergunta pertinente neste caso é não apenas se as crianças examinam posições contrárias, mas também em que extensão o fazem. A referência a múltiplos contraargumentos não só indica a capacidade do escritor lidar com estruturas textuais mais complexas, como também informa sobre seu nível de reflexão sobre o tema. Os números apresentados na Figura 2 abaixo permitem que se observe os níveis de elaboração de contra-argumentos nos textos de crianças das diferentes séries.

Dois elementos merecem destaque na Figura 2. Em primeiro lugar constata-se que, embora a tendência a examinar posições alternativas pareça se tornar sistemática em torno da quarta série (Figura 1), o grau de elaboração com que esta se realiza aumenta substancialmente em fases subseqüentes do desenvolvimento. O número médio de 
contra-argumentos praticamente duplica entre a quarta a sétima série (Prova de Mann-Whitney, unilateral, $U=$ $870 ; p=0,04$ na comparação entre as segunda e quarta séries e $U=1006 ; p=0,009$ entre as quarta e sétima). Apesar disto, nota-se que, mesmo no nível de escolaridade mais alto observado, o exame de posições contrárias ocorre de modo ainda bastante limitado. Menos de um contra-argumento, em média, é examinado por texto.

Impacto do Tema Discutido e da Estrutura Textual sobre a Produção de Contra-Argumentos

Finalmente, a terceira e última pergunta que esteve na base do presente estudo foi em que medida o engajamento das crianças no exame de posições contrárias no discurso escrito é sensível a elementos do contexto em que a argumentação se realiza. Mais especificamente investigou-se se o desempenho exibido pelas criança sofria variações em função do tópico sobre o qual os sujeitos argumentavam e da estrutura global do texto produzido. Nesse último caso testava-se a hipótese sugerida por Santos e Vasconcelos (1997) de que o exame de contra-argumentos seria favorecido se a argumentação solicitada às crianças fosse produzida no contexto de uma discussão entre dois personagens que divergiam quanto a um dado tema. A presença explícita de dois personagens
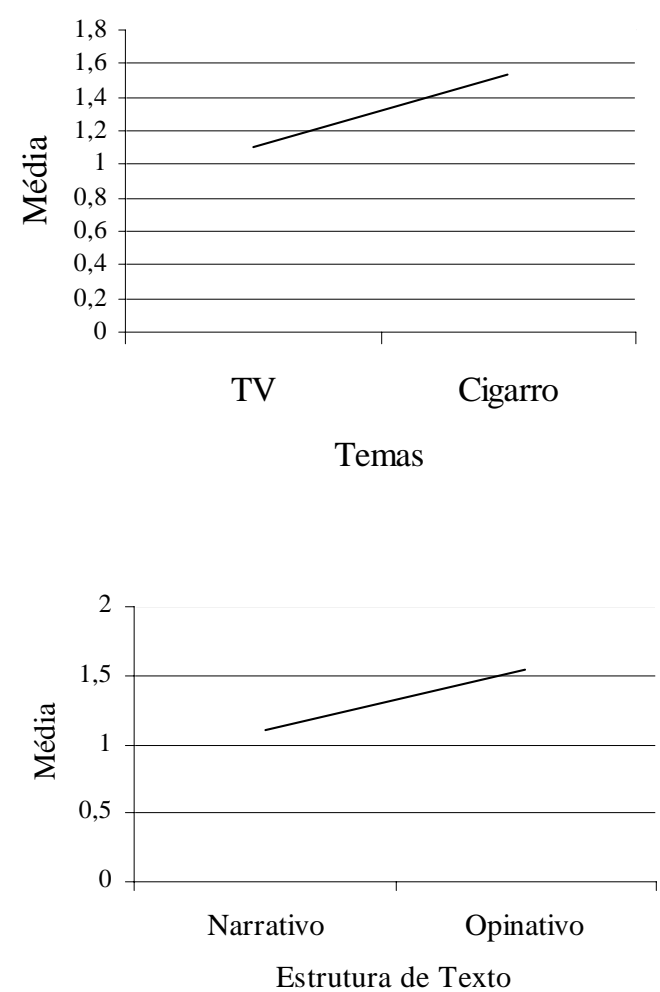

Figura 4. Número médio de justificativa por estrutura de texto em oposição, aliada à exigência de que a criança desse VOZ a estes personagens, funcionaria como uma pista intratextual que impulsionaria a produção de contraargumentos. O impacto do tópico discutido sobre a freqüência com que os textos integravam elementos contrários às posições dos seus autores foi investigado comparando-se as percentagens de textos sobre os temas $T V$ e Cigarro em que pelo menos um contra-argumento era considerado e o número médio de contra-argumentos identificados nos textos sobre estes temas.

Quando comparados os textos sobre os temas Cigarro e TV que continham no mínimo um contra-argumentos, percentuais semelhantes foram encontrados. Do mesmo modo, não se registrou nenhum efeito do tema discutido sobre o número médio de contra-argumentos incorporados ao texto. Idênticas medidas foram adotadas e idênticos resultados obtidos quando se investigou o possível impacto da estrutura global dos textos solicitados às crianças sobre a produção de contra-argumentos nos mesmos. A comparação entre os percentuais de textos narrativos e opinativos em que contra-argumentos eram referidos não sugeriu qualquer tendência significativa nos dados. Tampouco diferenças foram observadas quanto ao número médio de contra-argumentos encontrados nos textos narrativos e opinativos.

Um resultado algo surpreendente, porém, foi a constatação de um efeito do tópico discutido e da estrutura textual sobre o número médio de justificativas produzidas pelas crianças. Maior número de justificativas foi produzido na argumentação sobre o tema Cigarro que na argumentação sobre o tema TV (Prova de MannWhitney, unilateral, $U=2027 ; p=0,001$ ).

Figura 3. Número médio de justificativas por tema

Semelhantemente mais justificativas foram identificadas nos textos opinativos do que nos narrativos (Prova de Mann-Whitney, unilateral, $U=1923 ; p=0,0004$ ).

\section{Discussão}

O propósito deste estudo foi investigar os níveis de desempenho alcançados por crianças de diferentes idades e graus de escolaridade na realização de uma das operações críticas à produção de textos argumentativos escritos: a antecipação de contra-argumentos para um ponto de vista defendido. Para tanto, três perguntas específicas foram levantadas. Em primeiro lugar, indagouse em que medida as crianças tendiam a estabelecer uma estrutura dialógica para a argumentação que produziam numa condição de monólogo, típica da escrita (por estrutura dialógica entenda-se aqui aquela que incorpora tanto a justificação de pontos de vista quanto a antecipação 
de contra-argumentos a que estes estão sujeitos). Aliado a isto, indagou-se em que extensão o faziam (extensão medida pelo número de contra-argumentos antecipados). Finalmente, investigou-se qual o impacto que o tema abordado e a estrutura global do texto produzido teriam sobre a freqüência com que contra-argumentos seriam incorporados aos textos. As respostas que os resultados obtidos provêem para estas perguntas são sumariadas e discutidas a seguir.

No nível mais abrangente, os resultados apresentados acima indicam uma variação entre crianças de diferentes faixas etárias e níveis de escolaridade na freqüência com que produzem justificativas para suas posições e antecipam contra-argumentos para as mesmas nos textos que produzem. Esta variação, entretanto, apresenta especificidades relativas às diferentes operações argumentativas focalizadas neste trabalho. Já na segunda série, observa-se que $77 \%$ dos escritores geraram textos nos quais é possível identificar uma estrutura argumentativa formada por um ponto de vista e, no mínimo, uma justificativa, percentual este que não se altera significativamente nas séries subseqüentes. Tendência diversa constata-se entretanto com respeito ao manejo de contra-argumentos. Neste caso, os resultados mostraram um crescimento, ao longo da escolarização, na freqüência com que as crianças incorporam, no âmbito de um mesmo texto, os prós e os contras relativos a um tema polêmico. A antecipação de contra-argumentos nos textos produzidos por crianças da segunda-série (seteoito anos) mostrou-se deveras ocasional (27\%) vindo a ser sistemática apenas por volta da quarta série (dez-onze anos). Tais resultados confirmam observações registradas na literatura (com amostra internacional) quanto ao surgimento precoce da operação de justificação na escrita argumentativa infantil e permitem que se conclua não ser no plano da justificação que se situam os principais obstáculos a serem superados pelas crianças para que dominem a produção do tipo de texto em questão.

Em relação ao impacto de variáveis da situação de produção textual sobre o desempenho das crianças, duas hipóteses foram testadas. A primeira foi que a presença explícita de oponentes num texto, aliada à instrução dada à criança para que escrevesse uma discussão entre os mesmos, funcionaria como um recurso de facilitação procedural (expressão usada por De Bernardi \& Antolini, 1996), ou seja, uma pista intratextual que incentivaria a produção de contra-argumentos. Os resultados observados mostram, no entanto, que à presença de um personagem-oponente não se associou qualquer incremento no número de crianças que antecipam contraargumentos nos seus escritos nem no número médio de Psicologia: Reflexão e Crítica, 2000, 13(3), pp.351-361 contra-argumentos examinados em cada texto. Um efeito imprevisto observou-se porém em relação à produção de justificativas nos textos analisados. Em todas as séries, mais justificativas foram incorporadas aos textos opinativos do que aos narrativos. Resultados semelhantes foram obtidos na comparação entre os desempenhos das crianças que escreviam sobre diferentes tópicos. Nenhuma relação substancial foi no entanto observada entre produção de contra-argumentos e a natureza do tema abordado. Com relação à operação de justificação, por outro lado, constatou-se que as crianças produziram um maior número de justificativas nos textos sobre o tema Cigarro do que nos que abordaram o tema $T V$.

À primeira vista as observações acima parecem dar suporte à hipótese levantada por Golder e Coirier (1996) de que as operações de justificação e negociação são governadas por diferentes fatores. Segundo os autores, o aumento das marcas de negociação na escrita infantil (entre as quais a antecipação de contra-argumentos tem um papel central) dependeria prioritariamente de fatores gerais do desenvolvimento sóciocognitivo das crianças como, por exemplo, a progressiva capacidade dos indivíduos considerarem pontos de vista diferentes dos seus próprios e a exposição crescente a múltiplas perspectivas que o avanço na escolarização acarreta. A ampliação da estrutura de justificação no discurso argumentativo, por outro lado, dependeria sobretudo de fatores contextuais, tais como a necessidade de proponente e oponente chegarem a um acordo, as características dos interlocutores (Golder \& Coirier, 1996) e as exigências de situações de comunicação específicas (por exemplo, se o interlocutor solicita ou não uma justificativa (ver Orsolini, 1994).

Por mais atraente que a hipótese de Golder e Coirier (1996) possa parecer para a interpretação dos dados apresentados, algumas precauções merecem ser tomadas. A primeira é que, embora a antecipação de contraargumentos obviamente pressuponha uma capacidade do escritor lidar com a perspectiva de outrem, a ausência de contra-argumentos num texto por certo não poderia ser vista como indicativa da ausência, no argumentador, da capacidade de produzi-los. Esta afirmativa encontra apoio nos resultados obtidos nos estudos com crianças conduzidos por Santos (1997) e Vasconcelos (1998) e já mencionados acima. Em ambos os estudos, as autoras constataram a tendência das crianças a antecipar contraargumentos quando diretamente solicitadas a fazê-lo numa situação semelhante a uma entrevista, mas não os incluir nos textos que produziam minutos depois. Decorre desta observação que qualquer tentativa de explicar diferenças na produção de contra-argumentos, entre as 
séries investigadas, pela referência ao nível de desenvolvimento cognitivo geral das crianças aparece como, no mínimo, insuficiente.

Um segundo aspecto que aponta para os limites da hipótese explicativa acima é que, apesar do aumento constatado neste estudo na freqüência com que as crianças das faixas de idade e escolaridade mais avançadas lidam com contra-argumentos nos textos que produzem, não devem passar desapercebidas as importantes variaçõe intra-série que os dados permitem igualmente observar. Nota-se que, embora a quarta série apareça como um provável ponto crítico no aumento da freqüência com que contra-argumentos aparecem sistematicamente na escrita infantil (tanto em termos do número de texto que incorporam contra-argumentos como do número de contra-argumentos por texto), contra-argumentos ja se faziam presentes, em menor escala, nos textos de algun alunos de segunda série. Por outro lado é igualmente digno de nota que, mesmo entre os textos produzidos pelos escritores mais velhos e mais escolarizados, um terço não incorpora aos textos produzidos qualquer tipo de reflexão sobre posições contrárias às do autor. A presença de contra-argumentos na faixa menor de idade escolaridade bem como sua ausência na faixa maior parecem ser dificilmente explicáveis por perspectivas que remetem a fatores gerais do desenvolvimento cognitivo das crianças. A questão que parece pertinente levantar é o que levaria crianças, capazes de antecipar objeções às posições que defendem [como os estudos de Santos (1997) e Vasconcelos (1998) demonstram], a não incorporarem tais elementos aos textos que produzem.

Uma hipótese que nos parece plausível neste sentido é que a referência a perspectivas contrárias, quando solicitadas a expor o que pensavam sobre um tema, não apareça para as crianças como algo pertinente a ser feito. Neste sentido merece destaque o fato de que era precisamente esta a solicitação feita às crianças que produziram o texto opinativo. Ora, nos contextos de argumentação quotidiana dižer o que se pensa sobre um tema controverso assume quase sempre a conotação de defender o próprio lado numa questão, um significado mais compatível portanto com a produção de justificativas para este lado do que com a consideração de possíveis contra-argumentos. Semelhantemente, no texto narrativo proposto às demais crianças, a ênfase dada à necessidade dos personagens "chegarem a uma conclusão" poderia favorecer um maior foco na justificação do ponto de vista do personagem que o escritor definia como o que deveria vencer a discussão, do que na explicitação do que pensava o lado perdedor. Curiosamente "chegar a um acordo" nos textos produzidos pelas crianças quase sempre significou fazer prevalecer o lado defendido pelo personagem com o qual o escritor concordava. Em ambos os casos, portanto, um fator de ordem pragmática, ou seja, um aspecto das condições de produção definidas pelas instruções dadas às crianças, poderia estar na base dos resultados observados. Resultados de estudos diversos têm mostrado como, mesmo entre indivíduos adultos, a freqüência com que os indivíduos antecipam contra-argumentos para seus pontos de vista varia em função de como a situação de argumentação é definida pelas instruções dadas (ver Santos \& Santos, 1999, para uma revisão de estudos sobre o tema).

A hipótese explicativa levantada acima parece ser capaz de fornecer elementos não só para a compreensão da ênfase prioritária que os sujeitos deste estudo deram à produção de justificativas (em detrimento da antecipação de contra-argumentos), mas também para a compreensão da falta de efeito de variações na estrutura dos textos solicitados às crianças (opinativo vs. narrativo) sobre a produção de contra-argumentos pelas mesmas. O impacto (se algum) da pista intratextual oferecida (presença de personagem-oponente no texto narrativo) poderia ter sido neutralizado pela compreensão, da parte dos sujeitos, da argumentação como uma atividade que se define pela defesa um dos lados de uma polêmica. Esta hipótese parece ganhar força quando se observa o inesperado impacto de variações na estrutura do texto sobre a produção de justificativas. Um maior número de justificativas foi observada no texto opinativo, justamente aquele em que se pedia às crianças que dissessem "o que pensavam" sobre o tema.

Pesquisas posteriores deveriam portanto ser conduzidas de forma a revelar que fatores presentes nas condições de produção de argumentação na escrita poderiam estar associados à tendência do escritor incorporar ou não contra-argumentos ao texto produzido. Resultados de pesquisas como estas serão, por certo, relevantes na elaboração de recursos instrucionais que auxiliem o desenvolvimento de habilidades necessárias à produção de textos argumentativos.

\section{Referências}

Andriessen, J., Coirier, P., Roos, L., Passerault, J-M. \& Bert-Erboul, A. (1996). Thematic and structural planning in constrained argumentative text production. Em G. Rijlaarsdam, H. Bergh \& M. Couzijn (Orgs.), Current trends in research on writing: Theories, models, and methodology (pp. 237251). Amsterdam: Amsterdam University Press.

Banks-Leite, L. (1996, Setembro). L'árgumentation cher l'enfant d'âge préscolaire. Trabalho apresentado na Second Conference for Sociocultural Research, Genebra, Suíça. 
Coirier, P. (1996). Composing argumentative texts: Cognitive and/or textual complexity. Em G. Rijlaarsdam, H. van der Bergh \& M. Couzijn (Orgs.), Current trends in ressearch on writing: Theories, models, and methodology (pp. 317-338). Amsterdam: Amsterdam University Press.

Coirier, P., Coquin, D., Golder, C., \& Passerault, J-M. (1990). Le traitement cognitif du texte argumentatif: Recherches en production et en compréhension. Archives de Psychologie, 58, 315-348.

Coquin, D. \& Coirier, P. (1992). The discursive structures of argumentation: Effects of the type of referential space. European Journal of Psychology of Education, 3, 219-229.

De Bernardi, B. \& Antolini, E. (1996). Structural differences in the production of written arguments. Argumentation, 10, 175-196.

Dolz, J. (1996). Learning argumentative capacities. A study of the effects of a systematic and intensive teaching of argumentative discourse in 11-12 year old children. Argumentation, 10, 227-251

Eemeren, F. H. van, Grootendorst, R. \& Kruiger, T. (1987). Handbook of argumentation theory. Dordrecht, Holland: Foris.

Espéret, E., Coirier, P., Coquin, D. \& Passerault, J-M. (1987). L'implication du locuteur dans son discours: Discours argumentatifs formel et naturel. Argumentation, 1, 155-174.

Feilke, H. (1996). From syntactical to textual strategies of argumentation. Syntactical development in written argumentative texts by students aged 10 to 22. Argumentation, 10, 197-212.

Golder, C. (1992). Production of elaborated argumentative discourse: The role of cooperativeness. European Journal of Psychology of Education, 7,51-59.

Golder, C. \& Coirier, P. (1994). Argumentative text writing: Developmental Trends. Discourse Processes, 18, 187-210.

Golder, C. \& Coirier, P. (1996). The production and recognition of typological argumentative text markers. Argumentation, 10, 271-282

Holquist, M. (1990). Dialogism: Bakbtin and his world. New York: Routledge. Kail, M. \& Weissenborn, J. (1991). Conjunctions: developmental issues. Em G. Piéraut-Le Bonniec \& M. Dolitsky (Orgs.), Language bases... discourse bases (pp. 125-142). Amsterdam: John Benjamins.

Koch, I G. V. (1984). Argumutano e linguggem São Paulo: Cortez

Leitão, S. (no prelo). The potential of argument in knowledge building. Human Development.

Miller, M. (1987). Argumentation and cognition. Em M. Hickmann (Org.), Social and functional approaches to language and thought (pp. 225-249). San Diego, CA: Academic Pres

Orsolini, M. (1994). "Dwarfs do not shoot": An analysis of children's justifications. Cognition and Instruction, 11, 281-297.

Perera, K. (1984). Children's writing and reading. Oxford: Basil Blackwell.
Roussey, J. \& Gombert, A. (1996). Improving argumentative writing skills: Effect of two types of aids. Arrumentation, 2, 283-300.

Santos, C. M. M. \& Santos, S. L. (1999). Good argument, content and contextual dimensions. Em G. Rijlaarsdam \& E. Ésperet (Orgs. da série) e J. Andriessen \& P. Coirier (Orgs. do vol.), Studies in writing: Vol. 5. Foundations of argumentative text processing (pp. 87-113). Amsterdam: Amsterdam University Press.

Santos, S. L. (1993). The construction of arvuments: A comparison between strategies employed by students in experimental and naturalistic settings. Tese de Doutorado não publicada. Faculdade de Ciências Políticas e Sociais, Cambridge University, Cambridge, Inglaterra.

Santos, S. L. (1997). O desenvolvimento da escrita argumentativa. Arquivo. Brasileiros de Psicologia, 49, 23-42.

Santos, S. L. \& Vasconcelos, S. B. de A. (1997). The impact of text structure on children's argumentative writing [Resumo]. Resumos de comunicacões cientificas, Teaching and learning aryument - Second International Conference (p. 22). Londres.

Schiffrin, D. (1992). Discourse markers. Cambridge: Cambridge University Press.

Schneuwly, B. (1997). Textual organizers and text types: Ontogenetic aspects in writing. Em J. Costermans \& M. Fayol (Orgs.), Processing interclausal relationships: Studies in the production and comprehension of text (pp. 245-263). Mahwah, NJ: Lawrence Erlbaum.

Scinto, L. F. M. (1986). Written language and psychological development. Orlando: Academic Press.

Vasconcelos, S. B. de A. (1998). O desenvolvimento de babilidades argumentativas na escrita infantil. Dissertação de Mestrado não publicada. Curso de Pós-Graduação em Psicologia, Universidade Federal de Pernambuco, Recife, Pernambuco

Vieira, M. A. R. (1994). O desenvolvimento da elipse em textos narrativos, descritivos e argumentativos. Em M. A. Kato (Org.), A concepsão da escrita na crianca (pp. 165-192). Campinas: Pontes.

Werstch, J. (1991). Voices of the mind: A sociocultural approach to mediated action Cambridge, MA: Harvard University Press.

Sobre as autoras:

Selma Leitão é Psicóloga, Mestre em Psicologia pela Universidade Federal de Pernambuco, Doutora pela Universidade de Cambridge, Inglaterra (tese na área de Psicologia), Bolsista do CNPq e Professora dos Cursos de Graduação e Pós-Graduação em Psicologia (Área de Concentração: Psicologia Cognitiva) da Universidade Federal de Pernambuco.

Eliana G. da S. Almeida é Psicóloga e Bacharel em Psicologia pela Universidade Federal de

Pernambuco e foi Bolsista de Iniciação Científica pelo CNPq. 


\section{MESTRADO E DOUTORADO EM PSICOLOGIA DO DESENVOLVIMENTO}

$\mathrm{S}_{\mathrm{e}}$ se preparar para ser um pesquisador, professor universitário, ou mesmo um profissional de alta qualificação, o Programa de Pós-Graduação em Psicologia do Desenvolvimento da Universidade Federal do Rio Grande do Sul é o local que você procura. Desfrute de um ambiente acadêmico estimulante, onde alunos e professores convivem diariamente, com dedicação integral ao estudo e à pesquisa. Escreva-nos pedindo maiores informações.

INFORMAÇÕES E INSCRIÇÃO

UFRGS

UNIVERSIDADE FEDERAL
DO RIO GRANDE DO SUL

Instituto de Psicologia

PROGRAMA DE PÓS-GRADUAÇÃO EM PSICOLOGIA DO DESENVOLVIMENTO Secretaria do PPG em Psicologia do Desenvolvimento - UFRGS

Rua Ramiro Barcelos, 2600 Sala 110 Campus da Saúde

90035-003 Porto Alegre RS Brasil

Fone: (51) 3165246 Fax: (51) 3304797

http://urso.psico.ufrgs.br/ppg 